\title{
Nonlinear Control of a Pneumatic Actuator Based on a Dynamic Friction Model
}

\author{
Xuan Bo Tran \\ Hanoi University of Science and Technology, School of Transportation Engineering, Vietnam
}

This paper presents a new controller for the position of a pneumatic actuator. The controller is designed based on the multiple-surface sliding control method in combination with a frictional compensator. The multiple-surface sliding control method is applied to deal with the nonlinear characteristics of the pneumatic system, and the frictional compensator is applied to compensate for the friction force in the pneumatic actuator. The friction force is estimated based on a dynamic friction model (the LuGre model). Both simulation and experimental studies are done to evaluate the new controller. The evaluation results indicate significant improvement in the tracking position error of the new controller comparing to the multiple-surface sliding controller without friction compensation and other nonlinear controllers.

Keywords: pneumatic actuator, nonlinear control, friction compensation, dynamic friction model

\begin{abstract}
Highlights
- $\quad$ The new controller with friction compensation is proposed to control the position of a pneumatic cylinder.

- A minimal position peak error of $1 \mathrm{~mm}$ in steady-state condition can be obtained by the new controller with the step desired positions.

- A minimal position peak error of $2.2 \mathrm{~mm}$ in steady-state condition can be obtained by the new controller with the sinusoidal desired positions.

- $\quad$ By using the new controller, the relative position peak error is reduced by $10 \%$, and the relative root means squared (RMS) error is reduced by $6.5 \%$ in comparison to those of the multiple-surface sliding (MSS) controller without friction compensation.
\end{abstract}

\section{INTRODUCTION}

Pneumatic systems are widely used in industrial environments because they can provide many advantages, including low cost, high power-to-weight ratio, cleanness, ease of maintenance and replacement, cheap and available supply of air sources [1]. The pneumatic systems are also preferred in hot and/or humid environments where electric systems cannot be applied [2]. However, the compressibility of air, the nonlinearity of valves and friction in the pneumatic actuator are disadvantages of pneumatic systems. They cause the system to have high nonlinearities and modelling uncertainties [3] to [5]. Therefore, the application of linear control strategies is not suitable for achieving fast and highly accurate responses for the pneumatic actuators' position [6] to [8]. Many nonlinear and advanced control strategies have been employed to overcome the nonlinearities and uncertainties of the pneumatic systems. Bobrow and Jabbari [9] applied an adaptive control method based on the linear dynamics of the system to control the position of a pneumatic actuator. An adaptive fuzzyproportional-derivative (PD) controller was applied by Gao and Feng [10] for a one-degree pneumatic actuator. The full-state feedback was used in the control law for simultaneous parameter identification and tracking control. A combination of an adaptive control strategy and neural network was proposed by Chen et al. [11] for an electro-pneumatic servo system; the neural network was used to compensate for constructing a linearized model of the nonlinear system, and the robust adaptive controller was used to perform the model-matching for the uncertain linearized model of the system. Gross and Rattan [12] applied multilayer neural networks to compensate for the nonlinear nature of the dynamic system in conjunction with a proportional-integral-derivative (PID) feedback controller. The advantages of the above-advanced control strategies are that they allow updating system parameters and controller parameters. However, the quality of control performances greatly depends on the accuracy of the mathematical model of the system.

For the sliding mode control method, the first positioning application for pneumatic actuators was made by Paul et al. [13], Tang and Walker [14], and Surgenor and Vaughan [15]. This robust control method allows handling nonlinearities and compensates for the mismatched uncertainties of the mathematical model. However, one of the main drawbacks of this kind of control strategy for pneumatic systems is the need for acceleration feedback. To overcome this difficulty, Acarman et al. [16] and Liu et al. [17] used observers to estimate the acceleration and Pandian et al. [18] proposed the use of differential pressure feedback 
instead of acceleration feedback. Recently, Tsai and Huang [19] proposed a multiple-surface sliding controller (multiple-surface sliding (MSS) controller) for a pneumatic servo system. This controller was designed based on three sliding surfaces of position, velocity, and force, and this controller can exhibit the smallest control error among the controllers proposed thus far for the pneumatic actuators. However, the friction force was omitted in designing the MSS controller.

Armstrong-Helouvry [20] has shown that the control performances of a mechanical system can be significantly improved when the system controller is designed with friction compensation. Koch and Reichhartinger [21] and Ayalew and Jablokow [22] have applied the sliding model control method combined with model-based friction compensation in the controlling position of hydraulic actuators; they have achieved improved control performances. However, only simple nonlinear friction models such as static or Coulomb friction models were used in these studies. Tran and Yanada [23] have shown that the static friction models are not enough or useless in predicting dynamic friction behaviours in pneumatic cylinders, especially in the cases where the cylinders operate at low and oscillating velocity conditions. Therefore, dynamic friction models must be used to achieve highly accurate control performances for the pneumatic cylinder position. To date, many dynamic friction models have been proposed [24] to [29]. Among these, the dynamic LuGre friction model [25] is most used. This dynamic friction model can observe basic friction characteristics in most mechanical systems such as pre-sliding displacement, stick-slip motion, varying break-away force, and hysteresis. In addition, this model is quite suitable for theoretical calculations and is easy to implement. Tran and Yanada [23] have also experimentally examined the friction characteristics in pneumatic cylinders and have shown that the LuGre friction model can relatively adequately simulate all the measured friction characteristics. However, according to the author's survey, the application of the LuGre friction model combined with the MSS control method for controlling the position of the pneumatic actuators has not been studied.

In this paper, the multiple-surface control method combining with friction compensation based on the LuGre friction model for controlling the position of a pneumatic cylinder is studied. An electro-pneumatic servo system with a double-acting pneumatic cylinder and two pneumatic proportional flow control valves is considered to carry out this work. A general mathematical model of the system is built first. The control law of the new controller is then designed, and the absolute stability of the system is analysed. The new controller is evaluated using both simulations and experiments. The control performances of the new controller are compared with those of the MSS controller and other nonlinear controllers. Finally, the effectiveness of the new controller is shown.

The rest of this paper is organized as follows. In Section 1, the electro-pneumatic servo system is introduced, and its mathematical model is developed. Section 2 shows the synthesis of the system controller. A stable analysis of the closed-loop system is also shown in this section. The simulation evaluations are shown in Section 3, and the experimental evaluations are shown in Section 4. Finally, the main conclusion is drawn in Section 5.

\section{SYSTEM MODEL}

In this paper, we consider an electro-pneumatic servo system, as shown in Fig. 1. In this system, a doubleacting pneumatic cylinder is used to drive a load mass M.

The motion of the cylinder piston is controlled by two 3/2 electro-pneumatic proportional flow control valves, Valves 1 and 2 . Valve 1 is connected to the left chamber, and Valve 2 is connected to the right chamber of the cylinder. The valves' operation is controlled by the voltage signals $u_{1}$ and $u_{2}$. According to the characteristics of the valves used in the experimental

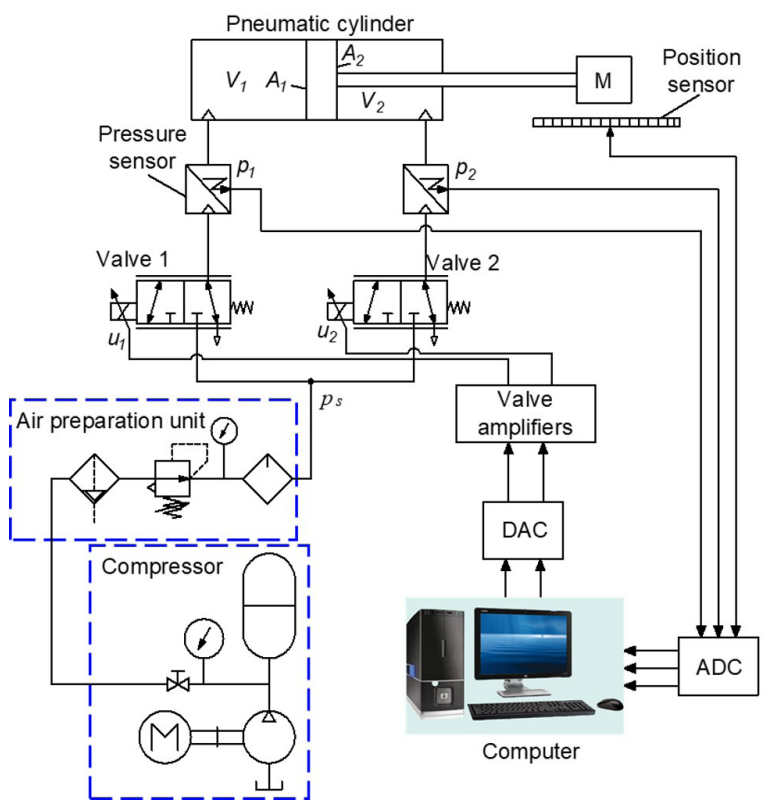

Fig. 1. Schematic diagram of the system 
system, as shown later in Section 4.1, the voltage values of $u_{1}$ and $u_{2}$ vary from 0 to $5 \mathrm{VDC}$. If $2.5 \leq u_{i} \leq 5$ $\operatorname{VDC}(i=1$ and 2$)$, the valves operate at the left side position, letting air from the compressor flow into the cylinder chambers; and if $0 \leq u_{i}<2.5 \mathrm{VDC}$, the valves operate at the right-side position, releasing air from the cylinder chambers to the atmosphere. Therefore, the cylinder piston will extend if $2.5 \leq u_{1} \leq 5 \mathrm{VDC}$ and $0 \leq u_{2}<2.5$ VDC. Conversely, the cylinder piston will extract if $0 \leq u_{1}<2.5 \mathrm{VDC}$ and $2.5 \leq u_{2} \leq 5 \mathrm{VDC}$. The flow rates through the valves depend on the voltage values of $u_{1}$ and $u_{2}$.

To develop a mathematical model of the system, the following assumptions are used:

a) The used air is an ideal gas, and its kinetic energy is negligible in the cylinder chambers.

b) The leakages of the cylinder are negligible.

c) The temperature variation in cylinder chambers is negligible with respect to the supply temperature.

d) The pressure and the temperature in the cylinder chambers are homogeneous.

e) The evolution of the gas in each chamber is a polytropic process.

f) The supply and ambient pressures are constant.

The mass flow rate $\dot{m}_{i}(i=1$ and 2$)$ that flows into or flows out from the chambers of the pneumatic cylinder can be derived in terms of the voltage inputs $u_{i}$ of the two valves as follow:

$$
\dot{m}_{i}=\left\{\begin{array}{ll}
\beta_{i b} p_{s} \sqrt{\frac{k}{R T}} H_{V 1}\left(u_{i}-2.5\right), & 2.5 \leq u_{i} \leq 5 \\
\beta_{i e} p_{i} \sqrt{\frac{k}{R T}} H_{V 2}\left(u_{i}-2.5\right), & 0 \leq u_{i}<2.5
\end{array},\right.
$$

where $p_{s}$ and $p_{i}$ are respectively the supply air pressure and the pressure in the cylinder's chambers, $k$ is the specific heat ratio, $R$ is the gas constant, and $T$ is the temperature of the supply source. $H_{V 1}$ and $H_{V 2}$ are respectively the valve coefficients. $\beta_{i b}$ and $\beta_{i e}$ are the pressure coefficients and are given by:

$\beta_{i b}=\left\{\begin{array}{ll}\sqrt{\frac{2}{k-1}}\left(\frac{p_{i}}{p_{s}}\right)^{\frac{k+1}{2 k}} \sqrt{\left(\frac{p_{i}}{p_{s}}\right)^{\frac{1-k}{k}}-1}, \frac{p_{i}}{p_{s}} \geq\left(\frac{2}{k+1}\right)^{k / k-1} \\ 0.58 & , \frac{p_{i}}{p_{s}}<\left(\frac{2}{k+1}\right)^{k / k-1}\end{array}\right.$,

$\beta_{i e}= \begin{cases}\sqrt{\frac{2}{k-1}}\left(\frac{p_{a t m}}{p_{i}}\right)^{\frac{k+1}{2 k}} \sqrt{\left(\frac{p_{a t m}}{p_{i}}\right)^{\frac{1-k}{k}}-1}, \frac{p_{a t m}}{p_{i}} \geq\left(\frac{2}{k+1}\right)^{k / k-1} \\ 0.58 & , \frac{p_{a t m}}{p_{i}}<\left(\frac{2}{k+1}\right)^{k / k-1}\end{cases}$
The dynamic relationship between the mass flow rates $\dot{m}_{1}, \dot{m}_{2}$ and the pressures $p_{1}, p_{2}$ in the cylinder chambers can be given by continuous equation as follows:

$$
\begin{aligned}
& \dot{p}_{1}=\frac{k}{V_{1}}\left(R T \dot{m}_{1}-p_{1} A_{1} v\right), \\
& \dot{p}_{2}=\frac{k}{V_{2}}\left(R T \dot{m}_{2}+p_{2} A_{2} v\right),
\end{aligned}
$$

where $v$ is the piston velocity, $A_{1}$ and $A_{2}$ are the piston areas. $V_{1}$ and $V_{2}$ are respectively to the volumes in the left and right chambers of the cylinder and are given as follows:

$$
\begin{aligned}
& V_{1}=V_{10}+A_{1} x, \\
& V_{2}=V_{20}+A_{2}(L-x),
\end{aligned}
$$

where $L$ is the piston stroke, $x$ is the piston position, $V_{10}$ and $V_{20}$ are, respectively, the dead volumes in the left and right chambers of the cylinder. The motion equation of the cylinder piston according to Newton's second law is given by:

$$
M a=p_{1} A_{1}-p_{2} A_{2}-F_{f r},
$$

where $M$ is the load mass of the piston, $a$ is the piston acceleration and $F_{f r}$ is the friction force. In [23], Tran and Yanada have measured the friction characteristics of the pneumatic cylinders and have shown that most of the measured characteristics can be simulated by the dynamic LuGre friction model with relatively good accuracy. Therefore, in this study, the LuGre model is used to describe the friction force $F_{f r}$ in the pneumatic cylinder. The LuGre friction model is described as follows:

$$
\begin{gathered}
\dot{w}=v-\frac{\sigma_{0} w}{q(v)}|v|, \\
q(v)=F_{c l}+\left(F_{s t}-F_{c l}\right) \exp ^{-\left(v / v_{s}\right)^{n}}, \\
F_{f r}=\sigma_{0} w+\sigma_{1} \dot{w}+\sigma_{2} v,
\end{gathered}
$$

where $w$ is the mean deflection of the elastic bristle between two surfaces made in contact, $\sigma_{0}$ is the stiffness of the elastic bristle, $q(v)$ is the Stribeck function, $F_{s t}$ is the static friction force, $F_{c l}$ is the Coulomb friction force, $v_{s}$ is the Stribeck velocity, $n$ is the exponent that affects the slope of the Stribeck curve, $\sigma_{1}$ is the micro-viscous friction coefficient, and $\sigma_{2}$ is the viscous friction coefficient.

Setting the valve signals $u_{1}$ and $u_{2}$ according to the control law $u$ of the system as follows:

where $p_{\text {atm }}$ is the atmosphere pressure. 


$$
\begin{aligned}
& u_{1}=2.5+u, \\
& u_{2}=2.5-u,
\end{aligned}
$$

then substituting Eq. (10) into Eq. (1) and along with Eq. (4), we obtain:

$\dot{p}_{1}=-\frac{k A_{1} p_{1} v}{V_{1}}+\frac{k \sqrt{k R T}}{V_{1}}\left[\begin{array}{c}(1+\operatorname{sign}(u)) \beta_{1 b} p_{\mathrm{s}} H_{V 1} \\ +(1-\operatorname{sign}(u)) \beta_{1 e} p_{1} H_{V 2}\end{array}\right] u$,

$\dot{p}_{2}=\frac{k A_{2} p_{2} v}{V_{2}}+\frac{k \sqrt{k R T}}{V_{2}}\left[\begin{array}{l}(1-\operatorname{sign}(u)) \beta_{2 b} p_{\mathrm{s}} H_{V 1} \\ -(1+\operatorname{sign}(u)) \beta_{2 e} p_{2} H_{V 2}\end{array}\right] u,(11)$

By setting $x_{1}=x ; x_{2}=\dot{x}_{1}$ and $x_{3}=p_{1} A_{1}-p_{2} A_{2}$, Eq. (6) then becomes:

$$
\begin{aligned}
& \dot{x}_{1}=x_{2}, \\
& \dot{x}_{2}=\frac{1}{M} x_{3}-\frac{F_{f r}}{M},
\end{aligned}
$$

Taking time derivative of $x_{3}$ along with Eq. (11) can be achieved as follows:

$$
\dot{x}_{3}=P(\mathbf{x}, t)+B(\mathbf{x}, t) u,
$$

where $\mathbf{x}=\left[\begin{array}{lll}x_{1} & x_{2} & x_{3}\end{array}\right]$ is state-vector and

$$
P(\mathbf{x}, t)=-\frac{k \mathrm{~A}_{1}^{2} p_{1} x_{2}}{V_{1}}-\frac{k \mathrm{~A}_{2}^{2} p_{2} x_{2}}{V_{2}},
$$

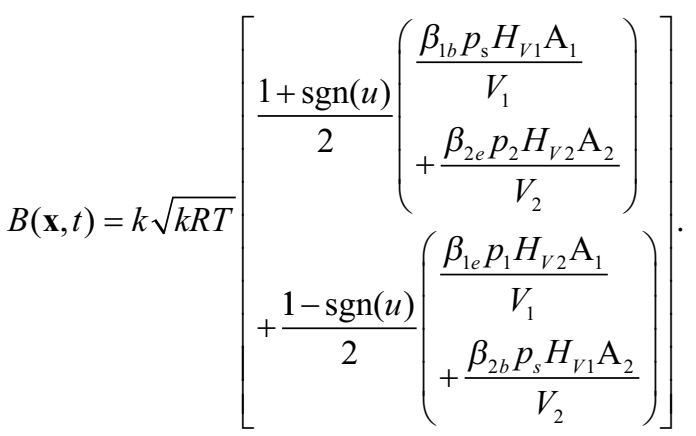

It can be realized from Eqs. (1) to (15) that the dynamics of the electro-pneumatic servo system are highly nonlinear due to the effects of compressibility of air in the cylinder chambers, the nonlinearity of the valves, and friction in the pneumatic cylinder.

\section{CONTROL STRATEGY}

\subsection{Control Design}

In this section, we design a controller so that the piston position $x_{1}$ can track the desired trajectory $x_{1 \mathrm{~d}}$ with high accuracy under the effect of the system nonlinearities (the compressibility of air in the cylinder chambers and the nonlinearity of the valves) and under the existence of friction. In [19], Tsai and Huang have applied the MSS controller to deal with the system nonlinearities and have obtained the smallest position error of $5 \mathrm{~mm}$ to sinusoidal desired position trajectories among the controllers proposed thus far for the pneumatic cylinders. However, the friction force was considered as a bounded uncertain force in the controller design. It is shown by ArmstrongHelouvry [20] that a controller combining with a friction compensator has the potential to improve the control performances of a control system. Therefore, in this study, we propose a new position controller of the cylinder piston by combining the MSS control method with a friction observer. The friction observer is designed based on the dynamic LuGre friction model. The block diagram of the closed-loop system using the new controller is shown in Fig. 2.

To design the new controller, the following assumptions of the system parameters are considered: i) the mass load is bounded by $M_{\min } \leq M \leq \mathrm{M}_{\max }$; ii) the piston velocity is bounded by $\left|x_{2}\right| \leq \alpha_{1}$; iii) the friction force is bounded by $\left|F_{f r}\right| \leq F_{s t}$; iv) the pressures

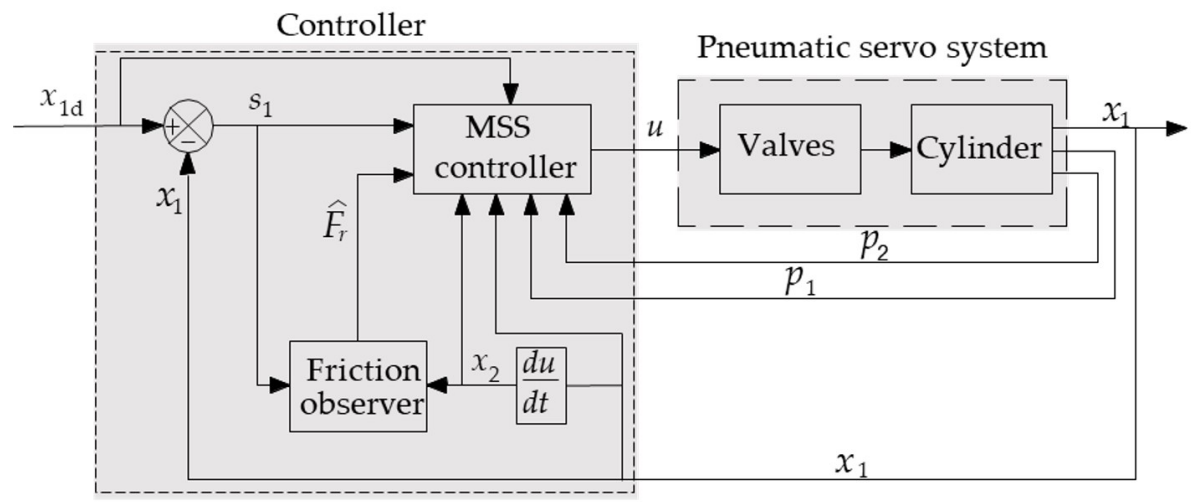

Fig. 2. Block diagram of the closed-loop system using new controller 
in the cylinder chambers are bounded by $p_{a t m} \leq p_{i} \leq p_{s}$, $i=1$ and 2 . Basing on these assumptions, the bounds for $F_{f r} / M$ and $P(\mathbf{x}, t)$ can be identified as follows:

$$
\begin{gathered}
\left|\frac{F_{f r}}{M}\right| \leq \frac{F_{s t}}{M_{\min }}=\alpha_{2}, \\
|P(\mathbf{x}, t)| \leq \frac{k p_{s} A_{1}^{2} \alpha_{1}}{V_{10}}+\frac{k p_{s} A_{2}^{2} \alpha_{1}}{V_{20}}=\alpha_{3} .
\end{gathered}
$$

The bound for $B(\mathbf{x}, t)$ can be found as:

$$
0<B_{\min } \leq B(\mathbf{x}, t) \leq B_{\text {max }},
$$

where $B_{\min }$ and $B_{\max }$ are determined from Eqs. (2), (3) and (15) as:

$$
\begin{aligned}
& B_{\text {max }}=0.58 p_{\mathrm{s}} k \sqrt{k R T}\left(\frac{H_{V 1} A_{1}}{V_{10}}+\frac{H_{V 2} A_{2}}{V_{20}}\right), \\
& B_{\text {min }}=0.58 p_{a t m}\left(\frac{2}{k+1}\right)^{\frac{k}{k-1}} k \sqrt{k R T}\left(\begin{array}{c}
\frac{H_{V 1} A_{1}}{V_{10}+A_{1} L} \\
+\frac{H_{V 2} A_{2}}{V_{20}+A_{2} L}
\end{array}\right),
\end{aligned}
$$

Let choosing an estimation $\widehat{B}$ of the gain $B(\mathbf{x}, t)$ as the mean of the above bounds:

$$
\widehat{B}=\left(B_{\min } B_{\max }\right)^{1 / 2},
$$

then bounds in Eq. (18) can be written in the form:

$$
\lambda^{-1} \leq \frac{B(\mathbf{x}, t)}{\widehat{B}} \leq \lambda,
$$

where $\lambda=\left(B_{\max } / B_{\min }\right)^{1 / 2}$.

Defining three sliding surfaces of position, velocity, and applied force as follows:

$$
\begin{aligned}
& s_{1}=x_{1}-x_{1 d}, \\
& s_{2}=x_{2}-x_{2 d}, \\
& s_{3}=x_{3}-x_{3 \mathrm{~d}},
\end{aligned}
$$

with the desired velocity and applied force are selected as follows:

$$
\begin{gathered}
x_{2 \mathrm{~d}}=\dot{x}_{1 \mathrm{~d}}-\tau_{1} \frac{s_{1}}{\theta_{1}}, \\
x_{3 d}=M \dot{x}_{2 d}+\widehat{F}_{f r}-\tau_{2} \frac{s_{2}}{\theta_{2}},
\end{gathered}
$$

where $\tau_{i}\left(i=1\right.$ and 2) are positive constants and $\theta_{i}$ are the boundary layer thicknesses of the surfaces $s_{i} . \widehat{F}_{f r}$ is the friction force that is estimated by the observer basing on the LuGre model as follows:

$$
\widehat{F}_{f r}=\sigma_{0} \hat{w}+\sigma_{1} \dot{\hat{w}}+\sigma_{2} \dot{x}_{1},
$$

$$
\dot{\hat{w}}=\dot{x}_{1}-\frac{\sigma_{0} \hat{w}}{q\left(\dot{x}_{1}\right)}\left|\dot{x}_{1}\right|-\tau_{z} s_{1},
$$

where $\tau_{\text {z }}$ is a positive constant. By introducing $\tilde{w}=w-w$ as the estimating error of the mean deflection of the contacting bristle and by combining with Eqs. (7) and (26), the time derivative of the error $\tilde{w}$ can be obtained as:

$$
\dot{\tilde{w}}=-\frac{\left|\dot{x}_{1}\right| \sigma_{0} \tilde{w}}{q\left(\dot{x}_{1}\right)}+\tau_{z} s_{1} .
$$

Taking time derivatives of $x_{2 d}$ and $x_{3 d}$ along with Eq. (12) obtains:

$$
\begin{gathered}
\dot{x}_{2 d}=\ddot{x}_{1 d}-\frac{\tau_{1}}{\theta_{1}}\left(x_{2}-\dot{x}_{1 d}\right), \\
\dot{x}_{3 d}=M \ddot{x}_{1 d}+M \frac{\tau_{1}}{\theta_{1}} \ddot{x}_{1 d}+\frac{\tau_{2}}{\theta_{2}} \dot{x}_{2 d} \\
-\left(M \frac{\tau_{1}}{\theta_{1}}+\frac{\tau_{2}}{\theta_{2}}\right)\left(\frac{1}{M} x_{3}-\frac{F_{f r}}{M}\right)+\dot{\widehat{F}}_{f r} .
\end{gathered}
$$

\section{Defining}

$\dot{x}_{3 d 1}=M \dddot{x}_{1 d}+M \frac{\tau_{1}}{\theta_{1}} \ddot{x}_{1 d}+\frac{\tau_{2}}{\theta_{2}} \dot{x}_{2 d}-\left(M \frac{\tau_{1}}{\theta_{1}}+\frac{\tau_{2}}{\theta_{2}}\right) \frac{x_{3}}{M}$, as known part and $\dot{x}_{3 d 2}=\left(M \frac{\tau_{1}}{\theta_{1}}+\frac{\tau_{2}}{\theta_{2}}\right) \frac{F_{f r}}{M}+\dot{\hat{F}}_{f r}$, as unknown part of $\dot{x}_{3 d}$, then we have:

$$
\dot{x}_{3 d}=\dot{x}_{3 d 1}+\dot{x}_{3 d 2} \text {. }
$$

In the ideal case where there is no friction force, the bounds of $\dot{x}_{2 d}, \dot{x}_{3 d 1}$ and $\dot{x}_{3 d 2}$ can be identified as

$$
\begin{gathered}
\left|\dot{x}_{2 d}\right| \leq \ddot{x}_{1 d \text { max }}+\frac{\tau_{1}}{\theta_{1}}\left(\alpha_{1}+\dot{x}_{1 d \text { max }}\right)=\dot{x}_{2 d \text { max }}, \\
\left|\dot{x}_{3 d 1}\right| \leq M_{\text {max }} \dddot{x}_{1 d \text { max }}+M_{\text {max }} \frac{\tau_{1}}{\theta_{1}} \ddot{x}_{1 d \text { max }}+\frac{\tau_{2}}{\theta_{2}} \dot{x}_{2 d \text { ma }} \\
+\left(M_{\max } \frac{\tau_{1}}{\theta_{1}}+\frac{\tau_{2}}{\theta_{2}}\right) \frac{p_{s} A_{1}-p_{a t m} A_{2}}{M_{\text {min }}}=\dot{x}_{3 d 1 \text { max }}, \\
\left|\dot{x}_{3 d 2}\right|=0 .
\end{gathered}
$$

Taking the Eqs. (12) and (13) into consideration, the time derivatives of three sliding surfaces can be derived as

$$
\begin{gathered}
\dot{s}_{1}=s_{2}-\tau_{1} \frac{s_{1}}{\theta_{1}}, \\
\dot{s}_{2}=\frac{1}{M} S_{3}-\frac{1}{M}\left(F_{f r}-\widehat{F}_{f r}\right)-\frac{1}{M} \tau_{2} \frac{s_{2}}{\theta_{2}},
\end{gathered}
$$




$$
\dot{s}_{3}=P(\mathbf{x}, t)+B(\mathbf{x}, t) u-\dot{x}_{3 d} .
$$

Eqs. (27) and (31) to (36) will be used later in Section 2.2 to analyse the stable properties of the closed-loop system. The control law of the system is proposed as follows:

$$
u=\frac{1}{\widehat{B}}\left(\dot{x}_{3 \mathrm{~d} 1}-P(\mathbf{x}, t)-\tau_{3} \frac{s_{3}}{\theta_{3}}\right) .
$$

where $\theta_{3}$ is the boundary thickness of the sliding surface $s_{3}$, and $\tau_{3}$ is a positive constant. It can be noted that adding the friction force estimate $\widehat{F}_{f r}$ in calculating the desired force $x_{3 d}$ in Eq. (24) affects the control law $u$ of the system in Eq. (37) through the sliding surface $s_{3}$.

\subsection{Stability Analysis}

This section presents the analysis of the stability properties of the closed-loop system basing on the Lyapunov direct method [30]. First, let us consider a Lyapunov function for the third sliding surface $s_{3}$ as $G_{3}=1 / 2 s_{3}^{2}$. Taking the time derivative of $G_{3}$ and combining it with the Eqs. (30), (36), and (37), we obtain:

$$
\begin{aligned}
\dot{G}_{3}= & s_{3}\left[\left(1-\frac{B(\mathbf{x}, t)}{\widehat{B}}\right) P(\mathbf{x}, t)+\left(\frac{B(\mathbf{x}, t)}{\widehat{B}}-1\right) \dot{x}_{3 d 1}-\dot{x}_{3 d 2}\right] \\
& -\frac{B(\mathbf{x}, t)}{\widehat{B}} \frac{\tau_{3}}{\theta_{3}} s_{3}^{2} .
\end{aligned}
$$

By selecting

$\tau_{3}=\frac{1}{\lambda}\left[(1+\lambda) \alpha_{3}+(1+\lambda) \dot{x}_{3 d 1 \max }+\gamma_{3}\right] \quad$ with $\quad \gamma_{3}>0$ along with Eqs. (31) to (33), then we obtain:

$$
\dot{G}_{3} \leq-\left|s_{3}\right|\left[\begin{array}{l}
(1+\lambda) \alpha_{3} \\
+(1+\lambda) \dot{x}_{3 d 1 \mathrm{max}}
\end{array}\right]\left(\frac{\left|s_{3}\right|}{\theta_{3}}-1\right)-\gamma_{3} \frac{s_{3}^{2}}{\theta_{3}},
$$

if we choose $\theta_{3} \leq\left|s_{3}\right|$ then $\dot{G}_{3} \leq-\gamma_{3} s_{3}^{2} / \theta_{3}<0$. This means that $s_{3}$ converges asymptotically to its boundary layer, i.e., the force $x_{3}$ converges to the desired force $x_{3 d}$. Similarly, let us consider a Lyapunov function for the second sliding surface $s_{2}$ as $G_{2}=1 / 2 s_{2}^{2}$. Taking the time derivative of $G_{2}$ and combining it with Eq. (35), we obtain:

$$
\dot{G}_{2}=s_{2} \dot{s}_{2}=s_{2}\left[\frac{1}{M} s_{3}-\frac{1}{M}\left(F_{f r}-\widehat{F}_{f r}\right)-\frac{1}{M} \tau_{2} \frac{s_{2}}{\theta_{2}}\right] .
$$

By assuming that the estimated friction force is bounded by $\left|\widehat{F}_{f r}\right| \leq F_{s t}$ and by selecting $\tau_{2}=M_{\max }\left[\frac{1}{M_{\min }} \theta_{3}+\frac{1}{M_{\text {min }}} 2 F_{s t}+\gamma_{2}\right]$ with $\gamma_{2}>0$, then,

$$
\dot{G}_{2} \leq\left|s_{2}\right| \frac{1}{M_{\min }}\left[\left(\left|s_{3}\right|-\theta_{3} \frac{\left|s_{2}\right|}{\theta_{2}}\right)+\left(1-\frac{\left|s_{2}\right|}{\theta_{2}}\right) 2 F_{s t}\right]-\gamma_{2} \frac{s_{2}^{2}}{\theta_{2}} .
$$

If we choose $\theta_{2} \leq \frac{\theta_{3}}{\left|s_{3}\right|}\left|s_{2}\right|$ then $\dot{G}_{2} \leq-\gamma_{2} \frac{s_{2}^{2}}{\theta_{2}}<0$. This proves that $s_{2}$ converges to its boundary layer asymptotically, i.e., the cylinder velocity $x_{2}$ converges to the desired velocity $x_{2 d}$. Finally, a Lyapunov function for the first sliding surface $s_{1}$ is defined as $G_{1}=\frac{1}{2} s_{1}^{2}+\frac{1}{2 \tau_{z}} \tilde{w}^{2}$. Taking the time derivative of $G_{1}$ and combining it with Eqs. (27) and (34), we obtain:

$$
\dot{G}_{1}=s_{1} s_{2}-\tau_{1} \frac{s_{1}^{2}}{\theta_{1}}-\frac{\left|\dot{x}_{1}\right| \sigma_{0} \tilde{w}^{2}}{\tau_{z} q\left(\dot{x}_{1}\right)}+\tilde{w} s_{1} .
$$

By selecting $\tau_{1}=\theta_{2}+\gamma_{1}$ with $\gamma_{1}>0$ and noting that $\tilde{w} s_{1} \leq \frac{1}{2} \tilde{w}^{2}+\frac{1}{2} s_{1}^{2}$, then we obtain:

$$
\begin{aligned}
\dot{G}_{1} & \leq\left|s_{1}\right|\left(\left|s_{2}\right|-\theta_{2} \frac{\left|s_{1}\right|}{\theta_{1}}\right)-\left(\frac{\gamma_{1}}{\theta_{1}}-\frac{1}{2}\right) s_{1}^{2} \\
& -\left(\frac{\alpha_{2} \sigma_{0}}{\tau_{z} q\left(\dot{x}_{1}\right)}-\frac{1}{2}\right) \tilde{w}^{2} .
\end{aligned}
$$

It can be noted in Eq. (8) that the Stribeck function $q\left(\dot{x}_{1}\right)$ is strictly positive and is bounded by $0<F_{c l} \leq q\left(\dot{x}_{1}\right) \leq F_{s t}$. So, if we select $\theta_{1} \leq \frac{\theta_{2}}{\left|s_{2}\right|}\left|s_{1}\right|$, $\gamma_{1}>\frac{\theta_{1}}{2}$ and $\tau_{z}<\frac{2 \alpha_{2} \sigma_{0}}{q\left(\dot{x}_{1}\right)}$ then $\dot{G}_{1}<0$. Therefore, $s_{1}$ converges asymptotically to its boundary layer, i.e., the piston position $x_{1}$ converges to the desired position $x_{1 d}$. This result, therefore, verifies the system's stability.

\section{SIMULATION EVALUATION}

In this section, simulation studies are carried out to evaluate the effectiveness of the new controller. Simulations were done by MATLAB/Simulink software. Both the new controller and the MSS controller were simulated with the same desired position inputs. The step and sinusoidal desired position inputs with different amplitudes and frequencies were used. The parameters of the system used in simulations are listed in Table 1. The maximum velocity of the piston was set to be $\alpha_{1}=1$ $\mathrm{m} / \mathrm{s}$ according to the cylinder's specification. The static parameters of the LuGre friction model were given by $F_{s t}=30 \mathrm{~N}, F_{c l}=5.6 \mathrm{~N}, v_{s}=0.01 \mathrm{~m} / \mathrm{s}, n=2.5$, $\sigma_{2}=25 \mathrm{Ns} / \mathrm{m}$ for the positive velocity direction (i.e., for extending stroke of the piston) and by $F_{s t}=25 \mathrm{~N}$, 
$F_{c l}=5.8 \mathrm{~N}, v_{s}=0.015 \mathrm{~m} / \mathrm{s}, n=1.2, \sigma_{2}=25 \mathrm{Ns} / \mathrm{m}$ for the negative velocity direction (i.e., for extending stroke of the piston). The dynamic parameters of the LuGre model were given by $\sigma_{0}=8 \times 10^{3} \mathrm{~N} / \mathrm{m}$ and $\sigma_{1}=0.1 \mathrm{Ns} / \mathrm{m}$ for both directions of the velocity. These parameters of the LuGre friction model were identified in advance for the pneumatic cylinder in a previous study [23]. The parameters of the controllers used in simulations were chosen as $\sigma_{1}=0.002, \sigma_{2}=0.1$, $\sigma_{3}=0.5, \gamma_{1}=0.01, \gamma_{2}=\gamma_{3}=1, \alpha_{2}=60$ and the parameter of the friction force observer was chosen as $\tau_{z}=5000$.

Table 1. System parameters used in simulation

\begin{tabular}{|c|c|c|c|}
\hline Parameter [unit] & Value & Parameter [unit] & Value \\
\hline$M[\mathrm{~kg}]$ & 0.5 & $H_{V 1}\left[\mathrm{~m}^{2} / \mathrm{V}\right]$ & $5 \times 10^{-7}$ \\
\hline$A_{1}\left[\mathrm{~m}^{2}\right]$ & $4.9 \times 10^{-4}$ & $H_{V 2}\left[\mathrm{~m}^{2} / \mathrm{V}\right]$ & $6 \times 10^{-7}$ \\
\hline$A_{2}\left[\mathrm{~m}^{2}\right]$ & $4.12 \times 10^{-4}$ & $T[\mathrm{~K}]$ & 295 \\
\hline$L[\mathrm{~m}]$ & 0.3 & $R[\mathrm{Nm} /(\mathrm{kgK})]$ & 287 \\
\hline$V_{10}\left[\mathrm{~m}^{3}\right]$ & $9.8 \times 10^{-7}$ & $p_{s}[$ bar] & 5 \\
\hline$V_{20}\left[\mathrm{~m}^{3}\right]$ & $8.24 \times 10^{-7}$ & $p_{\text {atm }}[\mathrm{bar}]$ & 0.1 \\
\hline$k$ & 1.3997 & & \\
\hline
\end{tabular}

Fig. 3 shows a comparison of the control performances obtained by simulations between the new controller and the MSS controller with a step desired position input of the piston position $x_{1 d}=0.25$ $\mathrm{m}$. The piston is set at an initial position of $0 \mathrm{~m}$. Fig. 3a shows that both the controllers exhibit good control performances with no overshoot. However, it can be observed that the rise time achieved by the new controller $(0.26 \mathrm{~s})$ is smaller than that of the MSS controller $(0.5 \mathrm{~s})$. In addition, the maximum tracking error in steady-state achieved by the new controller $(0.5 \mathrm{~mm})$ is also smaller than that of the MSS controller (1 mm) (Fig. 3b).

Fig. 4 shows simulation comparisons of the control performances between the new controller and the MSS controller for four different constant desired positions: $x_{1 d}=0.01 \mathrm{~m}$ (Fig 4a), $0.05 \mathrm{~m}$ (Fig. 4b), 0.1 $\mathrm{m}$ (Fig. 4c) and 0.2. $\mathrm{m}$ (Fig. 4c). The initial positions of the piston are $0 \mathrm{~m}$. Fig. 4 shows that the controller can provide shorter rise times and smaller position errors for four cases of the desired position. The maximum tracking errors obtained under steady-state conditions are also $0.5 \mathrm{~mm}$ for the new controller and $1 \mathrm{~mm}$ for the MSS controller.

Fig. 5 shows a comparison between the new controller and the MSS controller for a sinusoidal desired input $x_{1 d}=0.15+0.1 \sin (2 \pi f t) \mathrm{m}$ at the frequency $f=0.1 \mathrm{~Hz}$. The figure shows that the new controller can track the desired position faster, i.e., a shorter rise time, than the MSS controller. In addition, the tracking error achieved in a steady-state condition of the new controller is much smaller than that by the MSS controller. The maximum tracking error in the steady-state condition of the new controller is $1.5 \mathrm{~mm}$, whereas the maximum tracking error of the MSS controller is $4.8 \mathrm{~mm}$. Other comparisons between two controllers with higher frequencies of the desired position input $x_{1 d}=0.15+0.1 \sin (2 \pi f t)$ $\mathrm{m}$ are shown in Figs. 6 and 7. The position amplitude remains the same as in Fig. 5, but the frequency is increased to $0.5 \mathrm{~Hz}$ and $1 \mathrm{~Hz}$. As compared with Fig. 5, although the abilities to track the desired position of the two controllers are inferior when the frequency is increased, the new controller also provides smaller errors than the MSS controller. In Fig. 6 for $f=0.5$ $\mathrm{Hz}$, the maximum error in a steady-state condition is $2.8 \mathrm{~mm}$ for the new controller and is $6.5 \mathrm{~mm}$ for the MSS controller. In Fig. 7 for $f=1 \mathrm{~Hz}$, the maximum error in a steady-state condition is $4.5 \mathrm{~mm}$ for the new controller and is $7.8 \mathrm{~mm}$ for the MSS controller. The results obtained in Figs. 3 to 7 verify by simulation that the new controller can provide better control performances than the MSS controller.
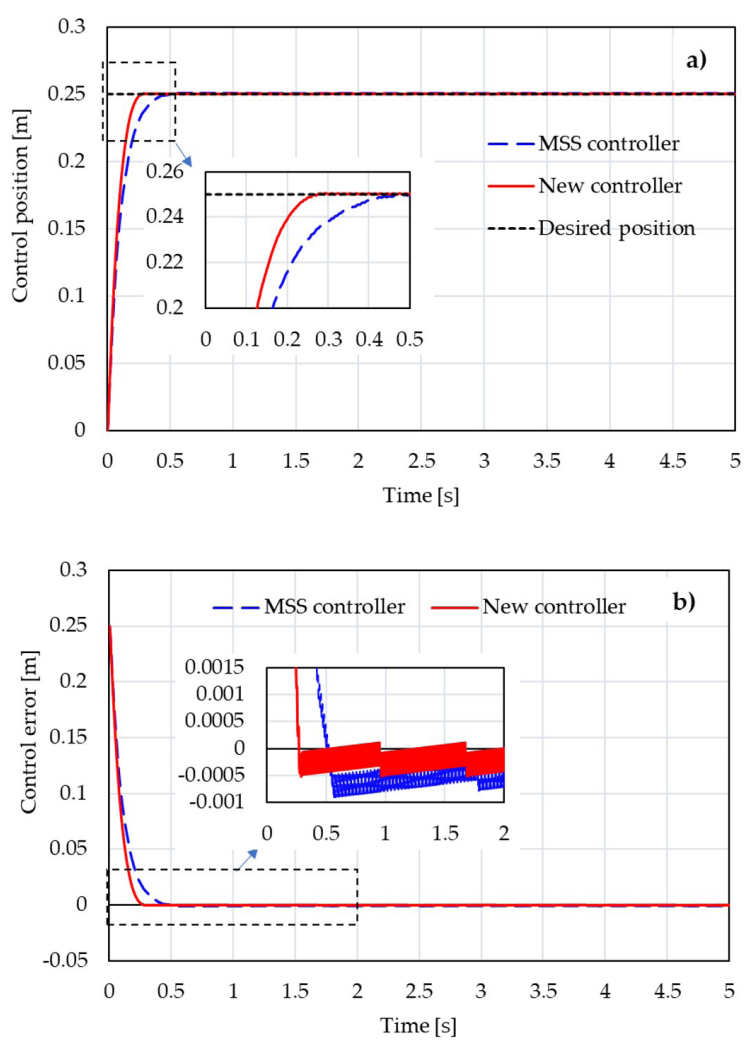

Fig. 3. Comparing control results of the new controller and the MSS controller with a step desired position input $x_{1 d}=0.25 \mathrm{~m}$; a) piston position, b) control position error (simulation) 

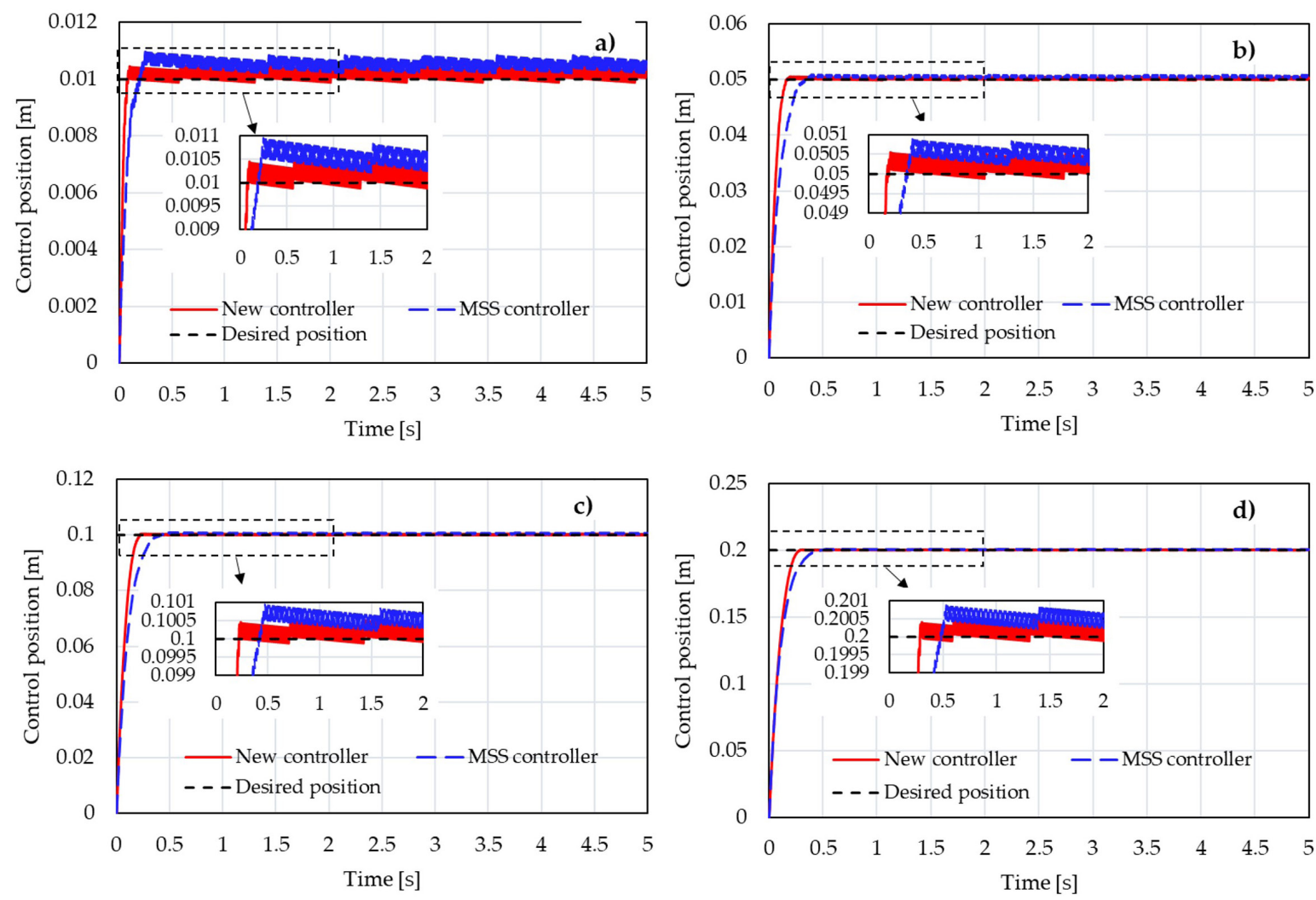

Fig. 4. Control results of the new controller and the MSS controller for different step desired positions; a) $x_{1 d}=0.01 \mathrm{~m}$, b) $x_{1 d}=0.05 \mathrm{~m}$; c) $x_{1 d}=0.1 \mathrm{~m}$; d) $x_{1 d}=0.2 \mathrm{~m}$ (experiment)
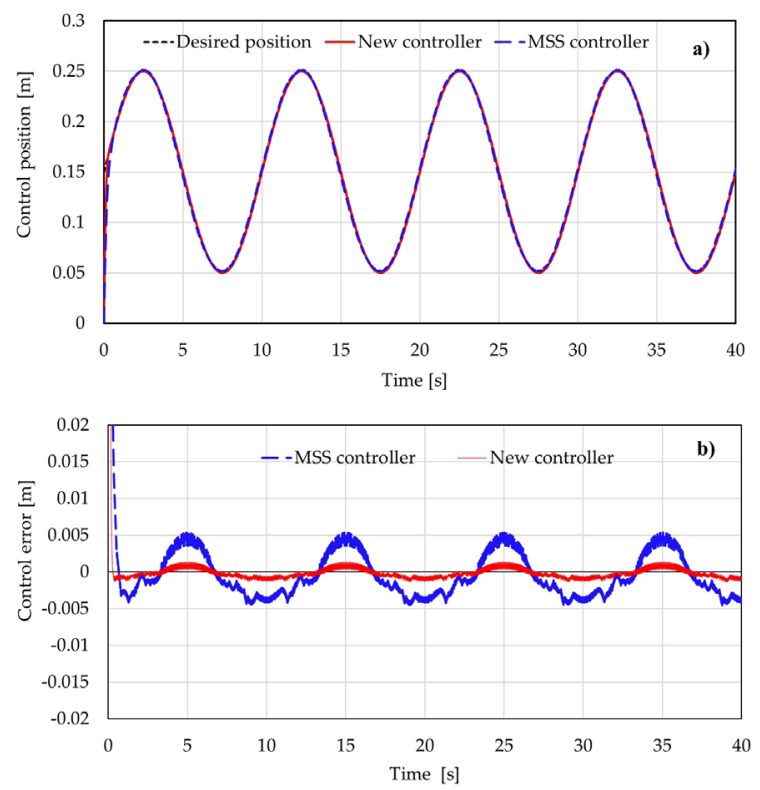

Fig. 5. Control performances of the new controller and of the MSS controller with a sinusoidal desired position

$x_{1 d}=0.15+0.1 \sin (2 \pi f t) \mathrm{m}, f=0.1 \mathrm{~Hz}$ by simulation; a) tracking position; b) tracking error
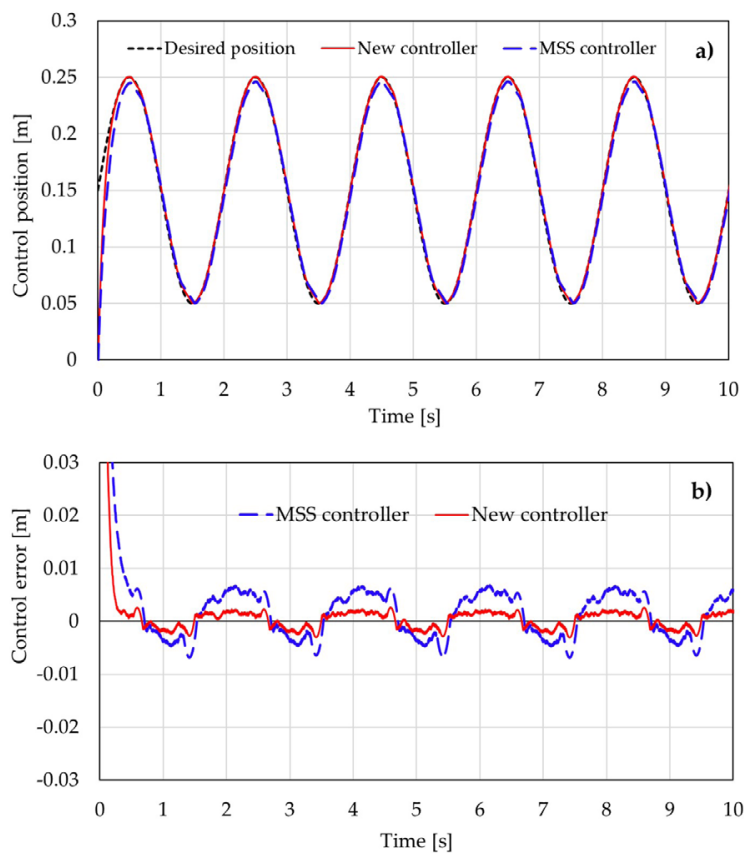

Fig. 6. Control performances of the new controller and of the MSS controller with a sinusoidal desired position

$x_{1 d}=0.15+0.1 \sin (2 \pi f t) \mathrm{m}, f=0.5 \mathrm{~Hz}$ by simulation; a) tracking position; b) tracking error. 

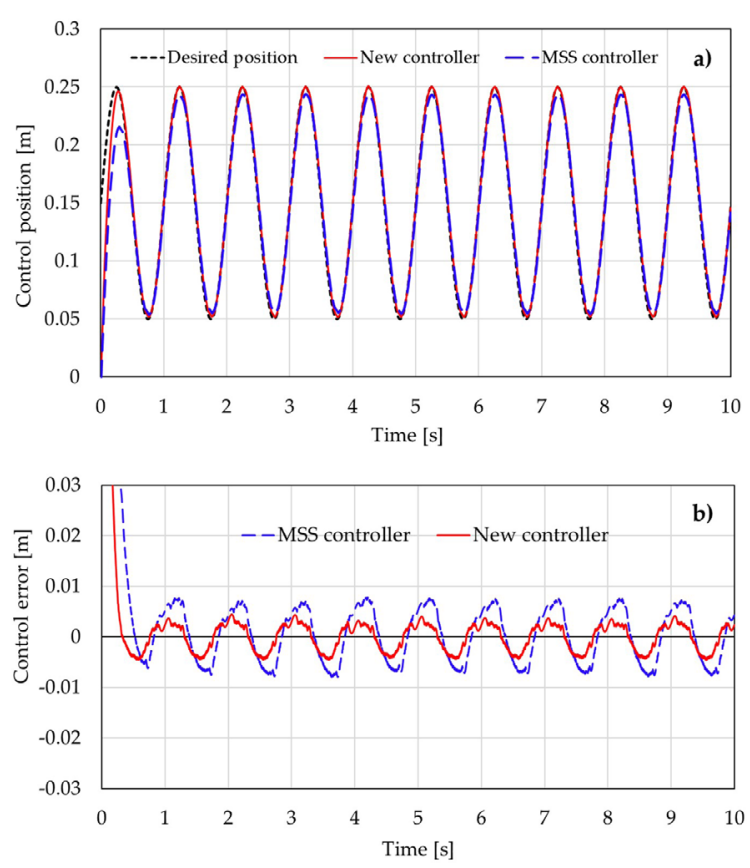

Fig. 7. Control performances of the new controller and of the MSS controller with a sinusoidal desired position

$x_{1 d}=0.15+0.1 \sin (2 \pi f t) \mathrm{m}, f=1 \mathrm{~Hz}$ by simulation;

a) tracking position; b) tracking error

\section{EXPERIMENTAL EVALUATION}

\subsection{Experimental System}

Fig. 8 shows the experimental system used for the experimental evaluation of the new controller. The system used a pneumatic double-acting cylinder (1). The piston rod was connected to a load mass
(2) which slides on a guiding bar (3). The load mass was set at $0.5 \mathrm{~kg}$. Two proportional pneumatic valves (4) were used to control flow rates supplying to the cylinder chambers. These valves were controlled by current signals ranging from $0 \mathrm{~A}$ to $1 \mathrm{~A}$. The current signals were supplied by two amplifiers (5). The input signals of the valve amplifiers are voltage values ranging from 0 VDC to 5 VDC. For the flow characteristic of the valves, it is noted that if the valves' inputs vary from 0.5 A to 1 A (corresponding to $2.5 \mathrm{VDC}$ to 5 VDC of the valve amplifiers' inputs), the valves will provide air from the supply source into the cylinder chambers and if the valves' inputs vary from $0 \mathrm{~A}$ to $0.5 \mathrm{~A}$ (corresponding to $0 \mathrm{VDC}$ to 2.5 VDC of the valve amplifiers' inputs), the valves will release air from the cylinder chambers to the atmosphere. A position sensor with a measuring range from $0 \mathrm{~m}$ to $0.3 \mathrm{~m} \mathrm{(6)} \mathrm{was} \mathrm{used} \mathrm{to} \mathrm{measure} \mathrm{the}$ piston displacement. Two pressures, $p_{1}$ and $p_{2}$, in the cylinder chambers were measured by two pressure sensors (7). A data acquisition card (8) that includes both 12 bits analogue-to-digital converter (ADC) and 12 bits digital-to-analogue converter (DAC) was used to acquire the displacement and the pressure signals from the sensors and to send the voltage signals to the valve amplifiers. The data acquisition device was connected to a personal computer (9). The main technical specifications of the devices are listed in Table 2. Microsoft Visual $\mathrm{C}++$ software was used to communicate between the data acquisition device and the computer. Each step of the experimental programme was executed in a period of $1.16 \mathrm{~ms}$.

The piston velocity that is used in calculating the control law was not measured in this experimental system. It was calculated by an approximate

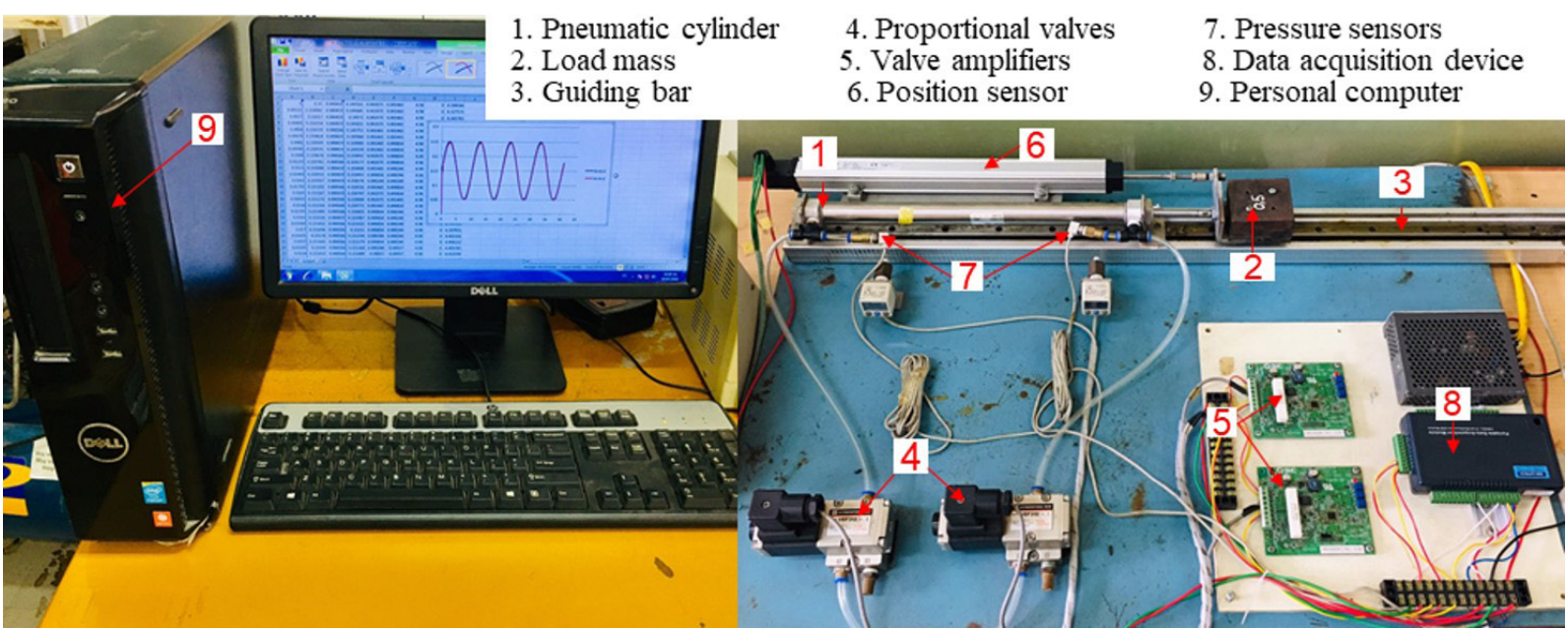

Fig. 8. Experimental system 
Table 2. Main equipment used in the experimental system

\begin{tabular}{|c|c|c|c|}
\hline Equipment & Model & Main technical specifications & Manufacturer \\
\hline Compressor & PK 1090A & $\begin{array}{l}\text { Maximum pressure: } 10 \mathrm{bar} \\
\text { Maximum flow rate: } 185 \mathrm{l} / \mathrm{min}\end{array}$ & PUMA \\
\hline Air preparation unit & GC 600-20 & $\begin{array}{l}\text { Maximum pressure: } 10 \mathrm{bar} \\
\text { Maximum flow rate: } 1000 \mathrm{l} / \mathrm{min} \\
\text { Filter element: } 40 \mathrm{~m}\end{array}$ & AIRTAC \\
\hline Pneumatic cylinder & CM2L25-300 & $\begin{array}{l}\text { Piston diameter: } 0.025 \mathrm{~m} \\
\text { Rod diameter: } 0.01 \mathrm{~m} \\
\text { Piston rod: } 0.3 \mathrm{~m} \\
\end{array}$ & SMC \\
\hline Proportional pneumatic valves & VEF3121-1-02 & $\begin{array}{l}\text { Maximum pressure: } 10 \mathrm{bar} \\
\text { Maximum flow rate: } 720 \mathrm{l} / \mathrm{min} \\
\text { Current input: } 0 \mathrm{~A} \text { to } 1 \mathrm{~A}\end{array}$ & SMC \\
\hline Valve amplifier & VEA 250 & $\begin{array}{c}\text { Voltage input: } 0 \text { VDC to } 5 \text { VDC } \\
\text { Curent output: } 0 \text { A to } 1 \mathrm{~A} \\
\text { Accuracy: } \pm 1 \% \text { F.S }\end{array}$ & SMC \\
\hline Position sensor & LWH0300 & $\begin{array}{l}\text { Measurement range: } 0 \mathrm{~m} \text { to } 0.3 \mathrm{~m} \\
\text { Accuracy: } 0.4 \% \text { F.S }\end{array}$ & NOVOTECHNIK \\
\hline Pressure sensor & PSE 540 & $\begin{array}{l}\text { Measurement range: } 0 \text { bar to } 10 \text { bar } \\
\text { Accuracy: } 2 \% \text { F.S }\end{array}$ & SMC \\
\hline Data acquisition card (ADC/DAC) & USB4711 & $\begin{array}{l}\text { Analog input channels: } 16 \\
\text { Analog output channels: } 2\end{array}$ & ADVANTECH \\
\hline Personal computer & Dell Vostro 260 & $\begin{array}{c}\text { CPU: Intel Core I3-2120 } 3.3 \mathrm{GHz} \\
\text { Memory: 8GB RAM }\end{array}$ & DELL \\
\hline
\end{tabular}

differentiation of the measured piston displacement. The noise in the calculated velocity signal was filtered using an acausal low-pass filter with a bandwidth of $30 \mathrm{~Hz}$. The compressed air was supplied to the system by a compressor through an air preparation unit, and the supply pressure $p_{s}$ was set at 5 bar.

\subsection{Experimental Results}

In this section, experimental performances of the new controller and the MSS controller are compared to evaluate the effectiveness of the new controller. Similarly to simulation, constant and sinusoidal desired position inputs were used. In addition, the control performances of the new controller are also compared to those of the other nonlinear controllers. The values of the controller's parameters and the parameters of the LuGre friction model were given as the same as those used in the simulation.

Fig. 9 compares the experimental performances between the new controller and the MSS controller with a desired step position input of $x_{1 d}=0.25 \mathrm{~m}$. Similarly to the results obtained in the simulation results in Fig. 3, both controllers exhibit accurate position tracking with the maximum tracking errors in a steady-state condition below $1 \mathrm{~mm}$, but the rise time of the piston obtained by the new controller $(0.2 \mathrm{~s})$ is less than the rise time of the MSS controller $(0.3 \mathrm{~s})$. It is additionally noted in Fig. 9 that at the beginning, the piston remains at its original position for $0.1 \mathrm{~s}$.
This result may be caused by the compressibility of the air in the cylinder chamber and/or by the delay characteristic of the pneumatic valves.
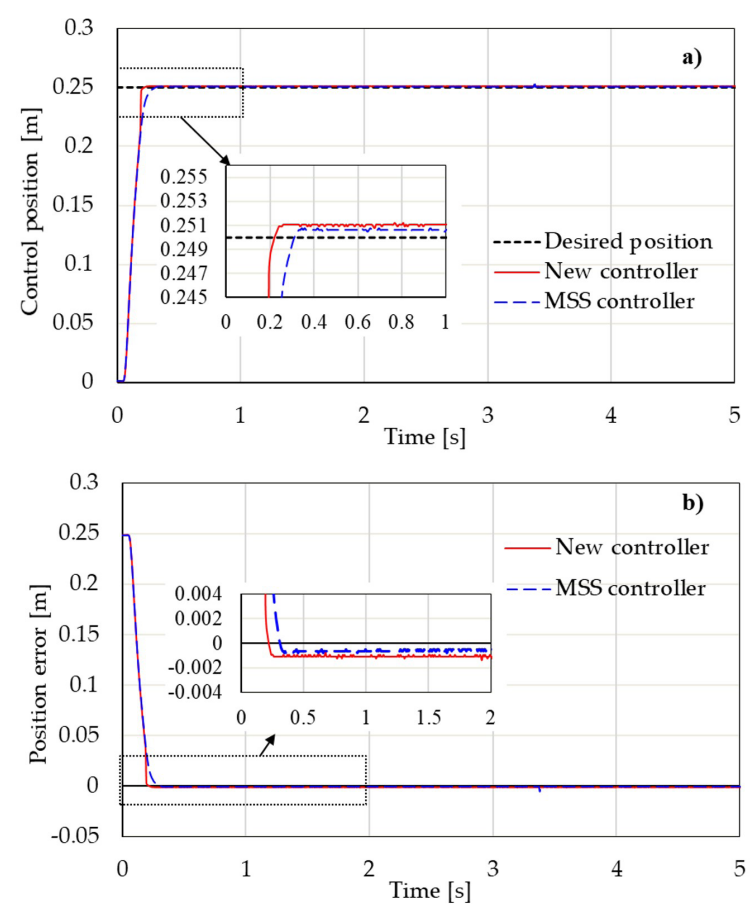

Fig. 9. Comparing control results of the new controller and the MSS controller with a desired constant position input

$x_{1 d}=0.25 \mathrm{~m}$; a) piston position,

b) control position error (experiment) 

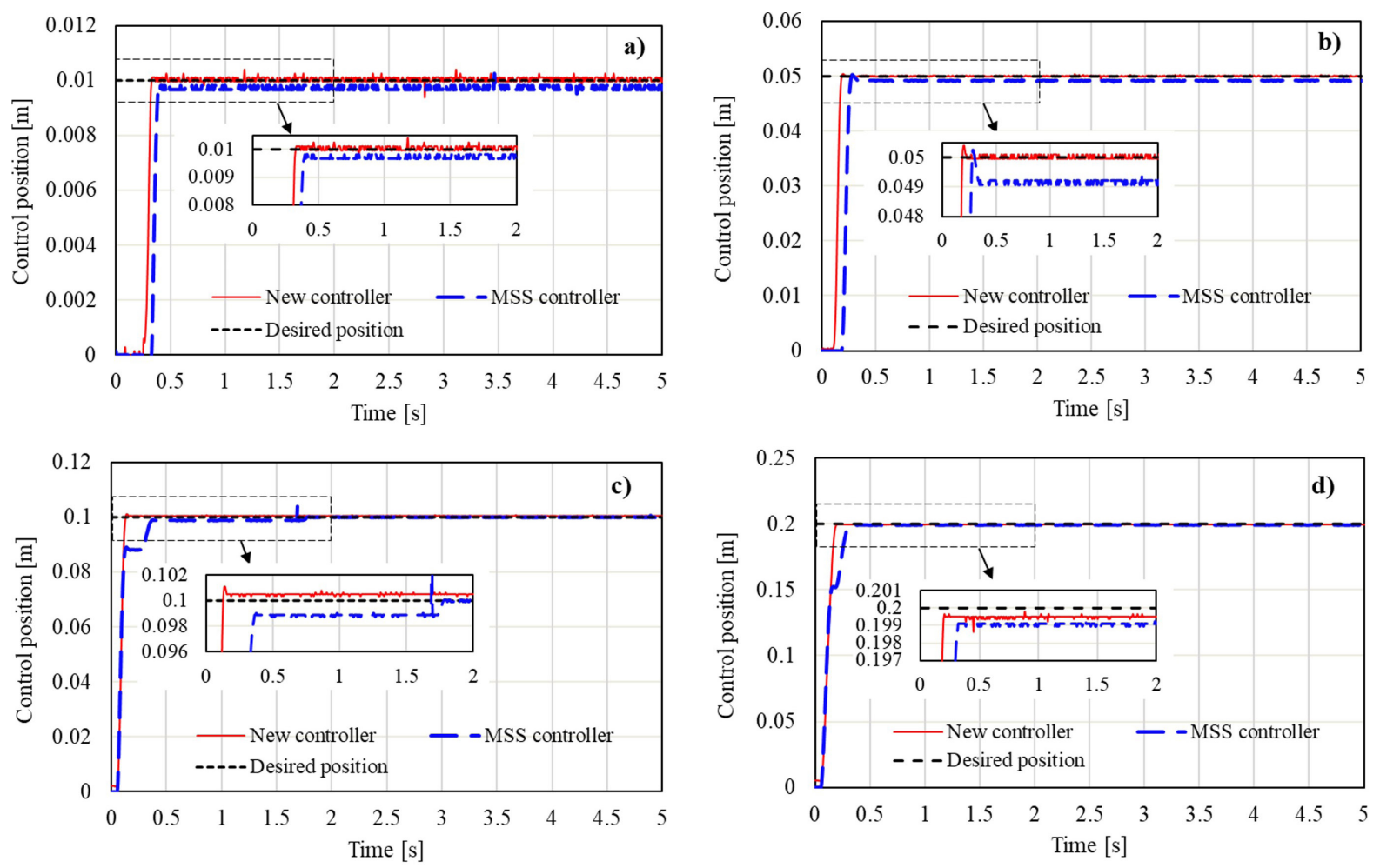

Fig. 10. Control results of the new controller and the MSS controller for different desired step position inputs; a) $x_{1 d}=0.01 \mathrm{~m}$, b) $x_{1 d}=0.05 \mathrm{~m}$; c) $x_{1 d}=0.1 \mathrm{~m}$; d) $x_{1 d}=0.2 \mathrm{~m}$ (experiment)

Fig. 10 compares the experimental performances between the new controller and the MSS controller at four step-desired positions: $0.01 \mathrm{~m}$ (Fig. 10a), 0.05 m (Fig. 10b), $0.1 \mathrm{~m}$ (Fig. 10c), and $0.2 \mathrm{~m}$ (Fig. 10d). Similarly to the simulation results in Fig. 4, Fig. 10 shows that the new controller provides better control performance than the MSS controller with shorter rise times and smaller steady-state errors in all cases. The maximum position errors in steady-state conditions are $0.5 \mathrm{~mm}$ for the new controller and $1 \mathrm{~mm}$ for the MSS controller. It can be additionally noted in Fig. 10 that the period at which the piston remains at its initial position is increased by reducing the desired position. This result can be explained by that when the desired position is reduced, the initial flow rate supplied to the cylinder is small and thus increases the delay time of the piston.

Fig. 11 shows an experimental comparison between the new controller and the MSS controller with a sinusoidal desired position $x_{1 d}=0.15+0.1 \sin$ $(2 \pi f t) \mathrm{m}$ at a frequency $f=0.1 \mathrm{~Hz}$. Fig. 11 shows that the peak position error obtained in a steady-state condition is $8.4 \mathrm{~mm}$ (corresponding to $4.2 \%$ of the maximum cross displacement) for the MSS controller and is $4.8 \mathrm{~mm}(2.4 \%)$ for the new controller. When
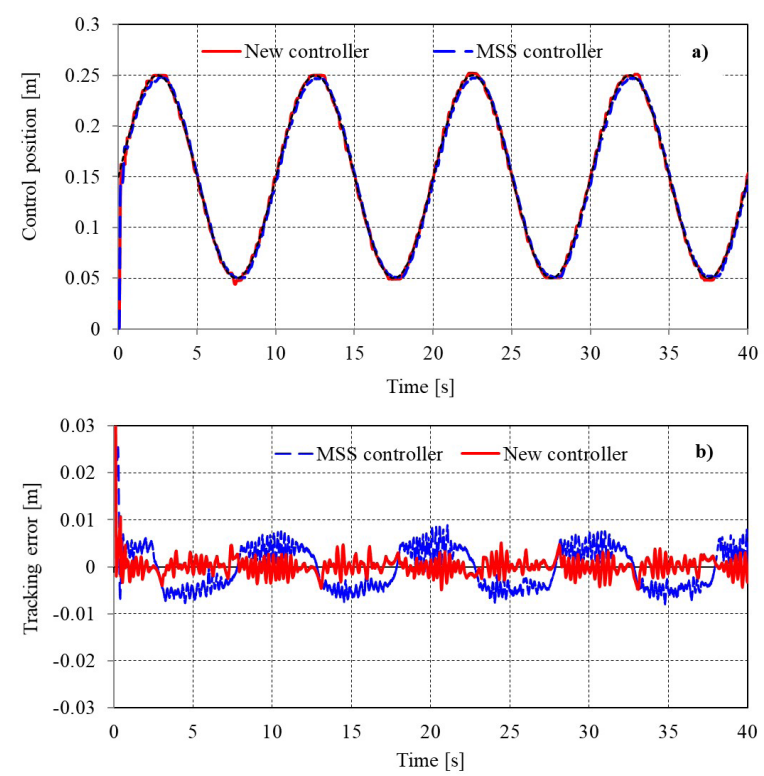

Fig. 11. Control performances of the MSS controller and the new controller with a sinusoidal input $x_{1 d}=0.15+0.1 \sin (2 \pi f t) \mathrm{m}$, $f=0.1 \mathrm{~Hz}$ by experiments; a) control position; $b)$ tracking error

calculating the root means squared error (RMS error) in a steady-state condition, the results show that the 
RMS error obtained for the MSS controller is 3.7 $\mathrm{mm}(1.85 \%$ of the maximum cross displacement) while the RMS error obtained for the new controller is $2.1 \mathrm{~mm}(1.05 \%)$. The calculated velocity and the estimated friction force by the new controller are shown in Fig. 12. When the piston starts moving, the friction force is suddenly increased to a very larger value of about $30 \mathrm{~N}$ in the first haft cycle of the piston motion. After that, the friction force reduces and varies under a trapezoidal form between the value from -13 $\mathrm{N}$ to $20 \mathrm{~N}$ in the steady-state condition. The maximum friction force at the positive velocity direction is larger than at the negative velocity direction. In Fig. 11, the large values of the tracking error obtained by the MSS controller appear mainly at high velocities, and they can be eliminated by the new controller. At high velocities, the friction force becomes large due to the effect of the viscous friction force. Thus, the compensation of friction to the MSS controller significantly reduces the tracking error at these velocities. The tracking errors of the two controllers achieved by experiments are larger than those achieved by simulation in Fig. 3. However, like the simulation results, the experimental result also shows the improvement in the control performances of the new controller comparing with the MSS controller.
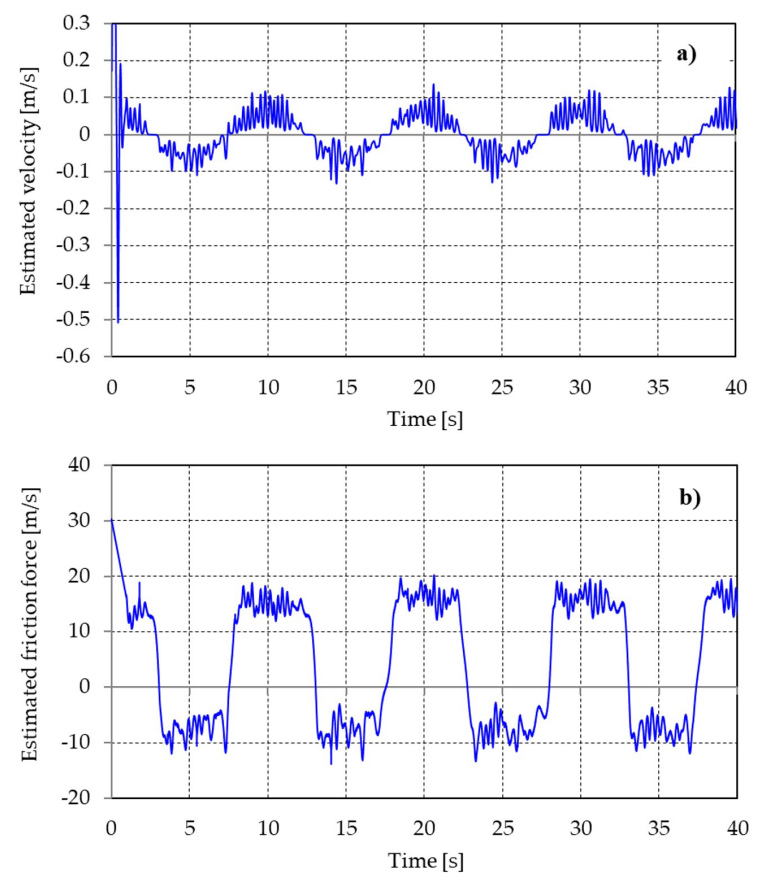

Fig. 12. Control performances of the MSS controller and the new controller with a sinusoidal input $x_{1 d}=0.15+0.1 \sin (2 \pi f t) \mathrm{m}$, $f=0.1 \mathrm{~Hz}$ by experiments; a) control position; b) tracking error
Fig. 13 compares the percentage rates of the peak position error and of the RMS error in steadystate condition between two controllers at different displacement amplitude values $(A)$ of the desired position input $x_{1 d}=0.15+A \sin (2 \pi f t) \mathrm{m}$. The varying frequency is fixed at $f=0.1 \mathrm{~Hz}$. The results show that both the peak error and the RMS error of both controllers increase with decreasing the displacement amplitude $A$. However, these errors are significantly reduced when using the new controller. When the amplitude $A$ varies from $0.01 \mathrm{~m}$ to $0.1 \mathrm{~m}$, the peak error can be reduced from $1.8 \%$ to $10 \%$, and the RMS error can be reduced from $0.8 \%$ to $6.5 \%$. The minimum peak error of $2.2 \mathrm{~mm}$ can be obtained at the amplitude $A=0.01 \mathrm{~m}$. This result of the new controller indicates better control performances than other nonlinear and robust control methods [9] to [21].

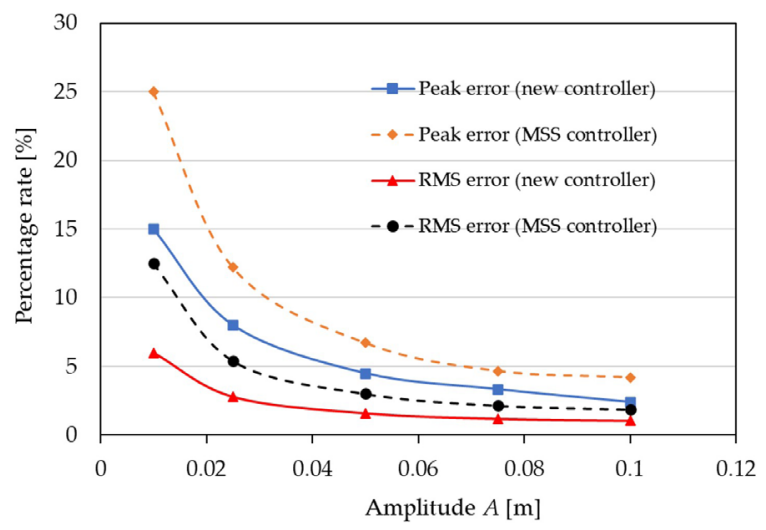

Fig. 13. Comparison of the percentage rate of peak error and RMS error between the new controller and the MSS controller at different displacement amplitudes $A$ and fixed frequency $0.1 \mathrm{~Hz}$ of the desired position input $x_{1 d}=0.15+A \sin (2 \pi f t) m$

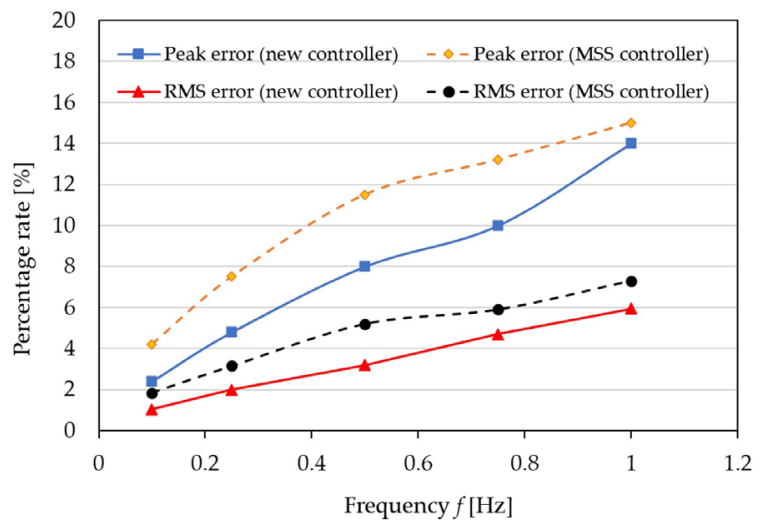

Fig. 14. Comparison of the percentage rate of peak error and RMS error between the new controller and the MSS controller at different frequencies $f$ and fixed displacement amplitude $A=0.1$ $\mathrm{m}$ of the desired position input $x_{1 d}=0.15+0.1 \sin (2 \pi f t) \mathrm{m}$ 

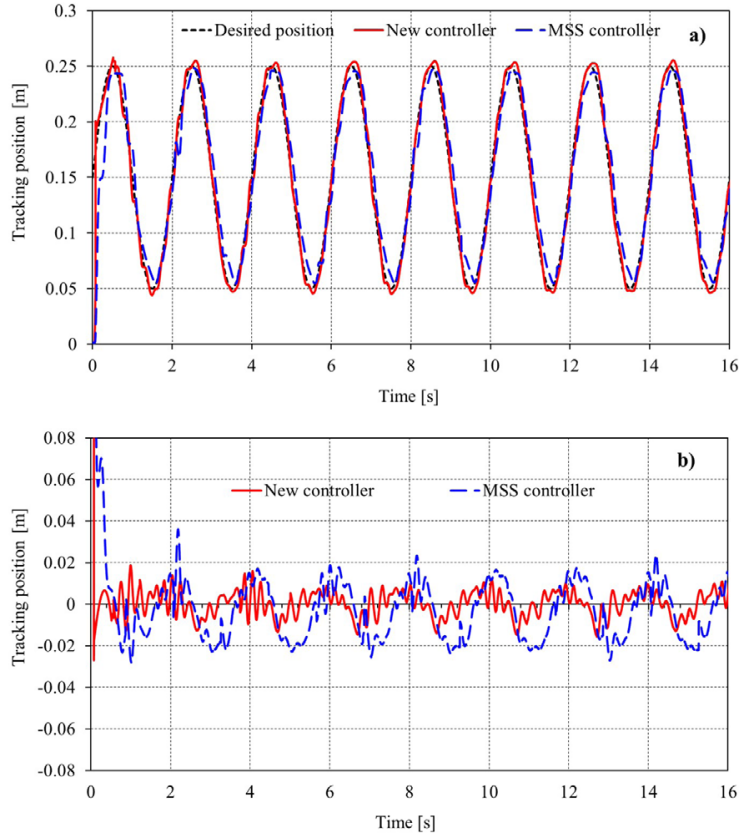

Fig. 15. Control performances of the MSS controller and the new controller with a sinusoidal input $x_{1 d}=0.15+0.1 \sin (2 \pi f t) \mathrm{m}$, $f=0.5 \mathrm{~Hz}$ by experiments; a) control position; b) tracking error

Fig. 14 compares the percentage rates of the peak position error and of the RMS error in steadystate condition between two controllers at different frequencies $(f)$ of the desired position input $x_{1 d}=$ $0.15+A \sin (2 \pi f t) m$. The displacement amplitude is fixed at $A=0.1 \mathrm{~m}$. The results show that both the peak error and the RMS error of both controllers grow with increasing the frequency. However, the peak error and the RMS error are also significantly reduced when using the new controller. When the frequency $f$ varies from $0.1 \mathrm{~Hz}$ to $1 \mathrm{~Hz}$, the peak error can be reduced from $1 \%$ to $3.5 \%$ and the RMS error can be reduced from $0.8 \%$ to $2 \%$. Figs. 15 and 16 show the control performances of two controllers at two frequencies $0.5 \mathrm{~Hz}$ and $1 \mathrm{~Hz}$.

\section{CONCLUSIONS}

In this study, a new controller was proposed for improving position control performances of a pneumatic cylinder. It was designed by combining the multiple-surface sliding control method with a modelbased friction compensator, which was designed based on the dynamic LuGre friction model. Both simulation and experimental studies were performed to evaluate the new controller. The study results show that by using the new controller, the relative position
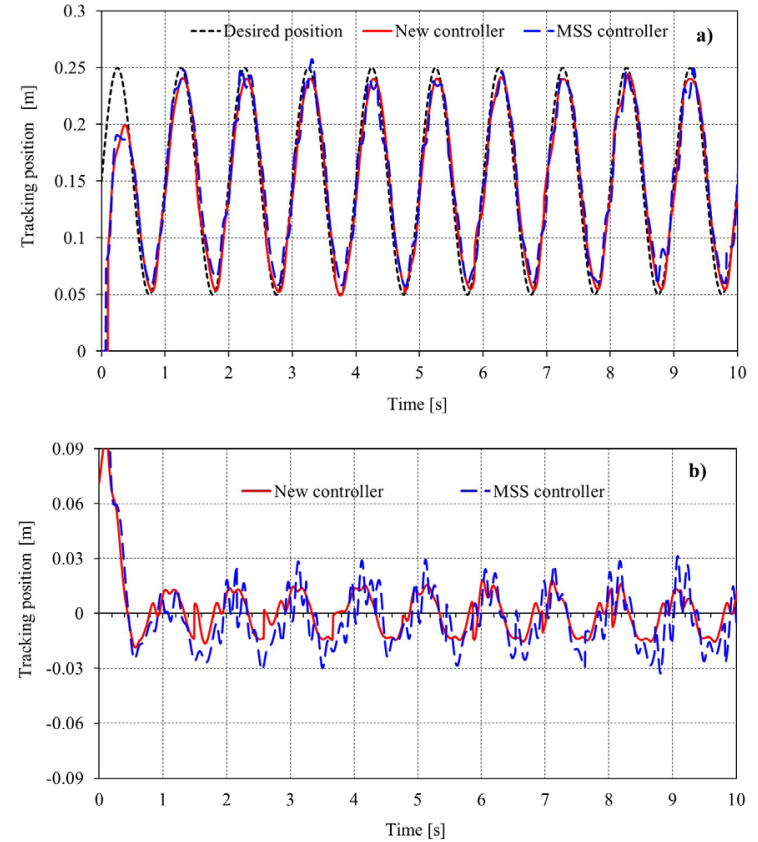

Fig. 16. Control performances of the MSS controller and the new controller with a sinusoidal input $x_{1 d}=0.15+0.1 \sin (2 \pi f t) \mathrm{m}$, $f=1 \mathrm{~Hz}$ by experiments; a) control position; b) tracking error

peak error is reduced $10 \%$, and the relative RMS error is reduced by $6.5 \%$ when comparing those of the MSS controller without friction compensation. The new controller also provides improved control error compared to other nonlinear and advanced controllers with a minimal peak error of $2.2 \mathrm{~mm}$. It is noted that the parameters of the LuGre model used in the friction observer in this study were identified in advance. Therefore, a methodology for online parameter estimation of the LuGre model when implementing the new controller will be considered in the future.

\section{ACKNOWLEDGEMENTS}

This research was an extension of the work in [31]. This research was funded by the Hanoi University of Science and Technology (HUST) under Project number T2020-PC-014.

\section{NOMENCLATURES}

$a$ piston acceleration, $\left[\mathrm{m} / \mathrm{s}^{2}\right]$

$A_{i} \quad$ piston area $(i=1,2),\left[\mathrm{m}^{2}\right]$

$B_{\max } \quad$ maximum value of the function $B(\mathbf{x}, t)$

$B_{\min } \quad$ minimum value of the function $B(\mathbf{x}, t)$

$\widehat{B} \quad$ estimated value of the function $B(\mathbf{x}, t)$

$F_{c l} \quad$ coulomb friction force, [N] 


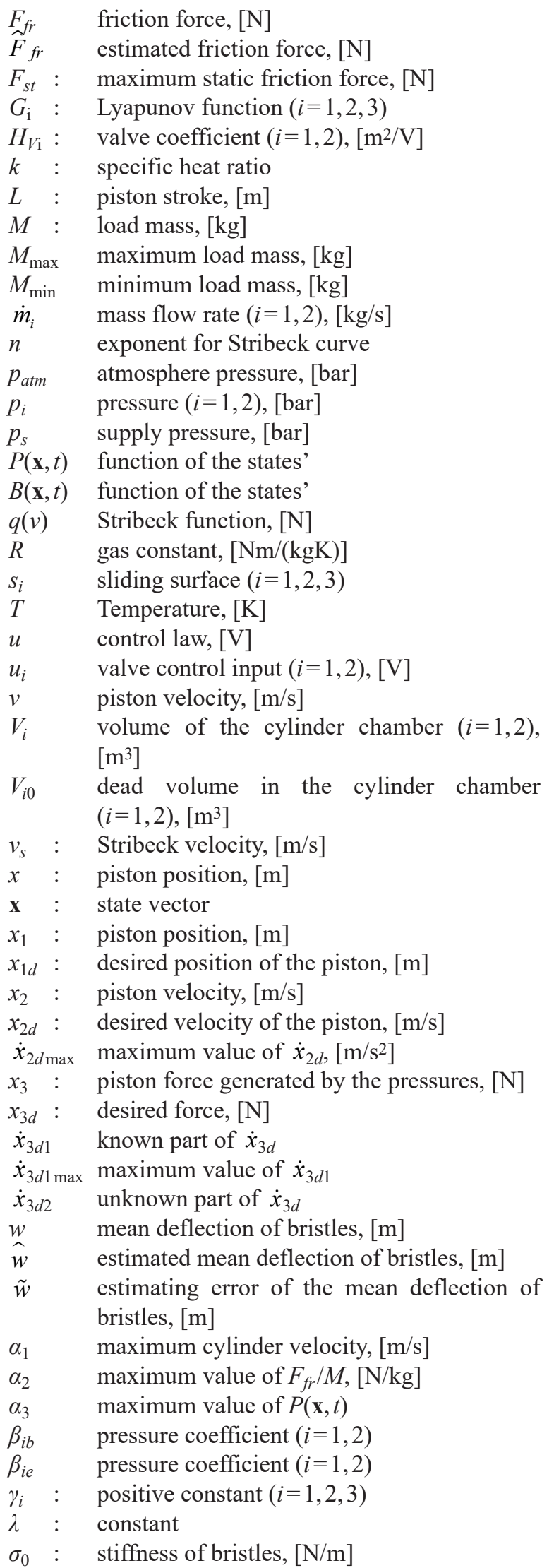

$\sigma_{2} \quad$ viscous friction coefficient, $[\mathrm{Ns} / \mathrm{m}]$

$\tau_{i} \quad$ positive constant $(i=1,2,3)$

$\tau_{z} \quad$ positive constant

$\theta_{i} \quad$ boundary layer thickness of the surfaces $s_{i}$ $(i=1,2,3)$

\section{REFERENCES}

[1] Beater, P. (2007). Pneumatic Drives: System Design, Modelling and Control. Springer, Berlin, DOI:10.1007/978-3-540-694717.

[2] Karponis, D., Koya, Y., Miyazaki, R., Kanno, T., Kawashima, K. (2019). Evaluation of a pneumatic surgical robot with dynamic force feedback. Journal of Robotic Surgery, vol. 13, p. 413421, D0I:10.1007/s11701-018-0878-2.

[3] Tressler, J.M., Clement, T., Kazerooni, H., Lim, M. (2002). Dynamic behavior of pneumatic systems for lower extremity extenders. Proceedings of IEEE International Conference on Robotics and Automation, p. 3248-3253, D0l:10.1109/ ROBOT.2002.1013727.

[4] Rao, Z., Bone, G.M. (2008). Nonlinear modeling and control of servo pneumatic actuators. IEEE Transaction on Control Systems Technology, vol. 16, no. 3, p. 562-569, Dol:10.1109/ TCST.2007.912127.

[5] Harris, P.G., O'Donnell, G.E., Whelan, T. (2012). Modelling and identification of industrial pneumatic drive system. The International Journal of Advanced Manufacturing Technology, vol. 58, p. 1075-1086, Dol:10.1007/s00170-011-3447-7.

[6] Wang, J., Pu, J., Moore, P. (1999). A practical control strategy for servo-pneumatic actuator systems. Control Engineering Practice, vol. 7, no. 12, p. 1483-1488, Dol:10.1016/S09670661(99)00115-X.

[7] Chillari, S., Guccione, S., Muscato, G. (2001). An experimental comparison between several pneumatic position control methods. Proceedings of the IEEE Conference on Decision and Control, vol. 2, p. 1168-1173, DOl:10.1109/CDC.2001.981043.

[8] Merola, A., Colacino, D., Cosentino, C., Amato, F. (2018). Model-based tracking control design, implementation of embedded digital controller and testing of a biomechatronic device for robotic rehabilitation. Mechatronics, vol. 52, p. 7077, D0I:10.1016/j.mechatronics.2018.04.006.

[9] Bobrow, J.E.; Jabbari, F. (1991). Adaptive pneumatic force actuation and position control. ASME Journal of Dynamic Systems, Measurement, and Control, vol. 113, no. 2, p. 267272, DOI:10.1115/1.2896374.

[10] Gao, X., Feng, Z.J. (2005). Design study of an adaptive fuzzy-PD controller for pneumatic servo system. Control Engineering Practice, vol. 13, no. 1, p. 55-65, Dol:10.1016/j. conengprac.2004.01.001.

[11] Chen, Y., Tao, G., Liu, H. (2019). High precision adaptive robust neural network control of a servo pneumatic system. Appled Sciences., vol. 9, no. 17, p. 1-17, Dol:10.3390/app9173472.

[12] Gross, D.C., Rattan, K.S. (1997). Pneumatic cylinder trajectory tracking control using a feedforward multilayer neural network, 
Proceedings of IEEE Aerospace and Electronics Conference, vol. 2, p. 777-784, DOl:10.1109/NAECON.1997.622728.

[13] Paul, A.K., Mishra, J.K.; Radke, M.G. (1994). Reduce order sliding mode control for pneumatic actuator. IEEE Transaction on Control Systems Technology, vol. 2, no. 3, p. 271-276. DOI:10.1109/87.317984.

[14] Tang, J.J., Walker, G.G. (1995). Variable structure control of a pneumatic actuator. ASME Journal of Dynamic Systems, Measurement, and Control, vol. 117, no. 1, p. 88-92, DOI:10.1115/1.2798526.

[15] Surgenor, B.W., Vaughan, N.D. (1997). Continuous sliding mode control of a pneumatic actuator. ASME Journal of Dynamic Systems, Measurement, and Control, vol. 119, no. 3, p. 578-581, D0l:10.1115/1.2801298.

[16] Acarman, T., Hatipoglu, C., Ozguner, U. (2001). A robust nonlinear controller design for a pneumatic actuator. Proceedings of the IEEE American Control Conference, vol. 6, p. 4490-4495, D0I:10.1109/ACC.2001.945686.

[17] Liu, Y.T, Kung, T.T, Chang, K.M., Chen, S.Y. (2013). Observerbased adaptive sliding mode control for pneumatic servo system. Precision Engineering, vol. 37, no. 3, p. 522-530, D0l:10.1016/J.precisioneng.2012.12.003.

[18] Pandian, S.R., Hayakawa, Y., Kanazawa, Y., Kamoyama, Y., Kawamura, S. (1997). Practical design of a sliding mode controller for pneumatic actuators. ASME Journal of Dynamic Systems,Measurement, and Control, vol. 119, no. 4, p. 666674, Dol:10.1115/1.2802376.

[19] Tsai, Y.C., Huang, A.C. (2008). Multiple-surface sliding controller design for pneumatic servo systems. Mechatronics, vol. 18, no. 9, p. 506-512, D0l:10.1016/j. mechatronics.2008.03.006.

[20] Armstrong-Helouvry, B. (1991). Control of Machines with Friction, Springer, Boston, D0I:10.1007/978-1-4615-3972-8.

[21] Koch, S., Reichhartinger, M. (2016). Observer-based sliding mode control of hydraulic cylinders in the presence of unknown load forces, e \& i Elektrotechnik und Informationstechnik, vol. 133, p. 253-260, D0l:10.1007/s00502-016-0418-6.

[22] Ayalew, B., Jablokow, K.W. (2006). Cascaded robust nonlinear position tracking control of an electrohydraulic actuator: sliding mode and feed forward. Proceedings of the ASME International Mechanical Engineering Congress and Exposition. Fluid Power Systems and Technology, p. 95-102, DOI:10.1115/IMECE2006-13943.

[23] Tran, X.B., Yanada, H. (2013). Dynamic friction behaviors of pneumatic cylinders. Intelligent Control and Automation, vol. 4, no. 2, p. 180-190, Dol:10.4236/ica.2013.42022.

[24] Armstrong-Helouvry, B., Dupont, P., Canudas de Wit, C. (1994). A survey of models analysis tools and compensation methods, for the control of machines with friction. Automatica, vol. 30, no. 7, p. 1083-1138, DOI:10.1016/0005-1098(94)90209-7.

[25] Canudas de Wit, C., Olsson, H., Aström, K.J., Lischinsky, P. (1995). A new model for control of systems with friction. IEEE Transaction on Automatic Control, vol. 40, no. 3, p. 419-425, DOI:10.1109/9.376053.

[26] Lampaert, V., Swevers, J., Al-Bender, F. (2002). Modification of the Leuven integrated friction model structure. IEEE Transaction on Automatic Control, vol. 47, no. 4, p. 683-687, DOI:10.1109/9.995050.

[27] Dupont, P., Hayward, V., Armstrong, B., Altpeter, F. (2002). Single state elastoplastic friction models. IEEE Transactions on Automatic Control, vol. 47, no. 5, p. 787-792, D0l:10.1109/ TAC.2002.1000274.

[28] Al-Bender, F., Lampaert, V., Swevers, J. (2005). The generalized Maxwell-slip model: a novel model for friction simulation and compensation. IEEE Transaction on Automatic Control, vol. 50, no. 11, p. 1883-1887, D0l:10.1109/TAC.2005.858676.

[29] Tran, X.B., Hafizah, N., Yanada, H. (2012). Modeling of dynamic friction behaviors of hydraulic cylinders. Mechatronics, vol. 22, no. 1, p. 65-75, D0l:10.1016/J.mechatronics.2011.11.009.

[30] Slotine, J.J.E., Li, W. (1991). Applied Nonlinear Control, Prentice Hall, London.

[31] Tran, X.B., Nguyen, V.L., Nguyen, N.C., Pham, D.T., Phan, V.L. (2020). Sliding mode control for a pneumatic servo system with friction compensation. In: Sattler, K.U., Nguyen, D., Vu, N., Tien Long, B., Puta, H. (eds). Advances in Engineering Research and Application. ICERA 2019. Lecture Notes in Networks and Systems, vol. 104. Springer, Cham, DOl:10.1007/978-3-030-37497-6_75. 